\title{
Seasonal activity of two human-biting ticks
}

Robert S. Lane

\begin{abstract}
In northern California, the western black-legged tick is considered the primary vector of the spirochete that causes Lyme disease. That tick and the Pacific Coast tick also can be carriers of several other diseases. In one study to learn when humans and other animals are at greatest risk of exposure, adults of both tick species were found to be most abundant during the cooler seasons.
\end{abstract}

Lyme disease, also known as Lyme borreliosis, is the most commonly reported vectorborne infection of humans in the United States and other temperate regions of the world, such as Europe. The disease initially appears with a slowly expanding, ring-like skin rash in $50 \%$ to $75 \%$ of patients, often accompanied by flu-like symptoms. Cardiac, neurologic, arthritic, and sometimes further dermatologic manifestations may occur weeks to months later. First recognized in the United States in Lyme, Connecticut, in the mid-1970s, the disease is caused by a spirochete, a flexible, helical, slender bacterium, named Borrelia burgdorferi for its discoverer, Dr. Willy Burgdorfer, of the U.S. Public Health Service, Rocky Mountain Laboratories.

The Lyme disease spirochete is transmitted to humans and other vertebrates mainly by the bite of several species of hard-bodied (ixodid) ticks. In northern California and southern Oregon, the western black-legged tick, Ixodes pacificus, a vicious biter of humans, has been implicated as the primary vector of the spirochete to humans; dogs, and possibly other domestic animals such as horses. Both the nymphs and adult females commonly attach themselves to humans. This tick has been reported from 53 of California's 58 counties at elevations from sea level to over 7,000 feet. Approximately 80 species of lizards, birds, and mammals have been recorded as hosts of this tick throughout its distribution in western North America (along the Pacific Coast from California north to British Columbia, and in Nevada, Utah, and Idaho).

Since 1974, I have been studying the ecology and epidemiology of several tick-borne bacterial, rickettsial, and viral diseases in northern California, with emphasis on Lyme disease during the 1980s. Many of these investigations have been conducted at the University of California Hopland Field Station in Mendocino County, an endemic area for Lyme disease, Rocky Mountain spotted fever, tularemia, and other tickborne diseases.

More recently, the field studies of Lyme disease were expanded to the UC Sierra Foothill Range Field Station in Yuba County. In 1987, the investigation reported here was undertaken at both field stations to determine the seasonal distribution and abundance of adults of the western blacklegged tick and the Pacific Coast tick, Dermacentor occidentalis. The latter is another human-biting tick with a broad host range; in California, it has been collected from approximately 25 species of small to large-sized mammals or vegetation in 54 counties. Several bacterial, rickettsial, and viral agents have been detected in or isolated from the Pacific Coast tick in California. This tick is known also from Oregon and northern Baja California, Mexico.

\section{Procedures}

The Hopland Field Station (HFS) is a 5,300-acre agricultural sciences research facility on the western slopes of the Mayacmas Mountains in the Russian River Valley in northwestern California. The terrain consists of rolling hills and scattered ravines covered by seven major vegetational types including grass, woodlandgrass, dense woodland, and chaparral. Elevations are between 500 and 3,000 feet. The climate is Mediterranean with hot, dry summers and cool, wet winters.

The Sierra Foothill Range Field Station (SFRFS) also has hot, dry summers and cool, wet winters. The soil, terrain, and vegetation are typical of the steep western Sierra Nevada foothills mixed with small local valleys.

At Hopland, ticks were swept from chaparral with a flannel tick-drag about 10
Male (above left) and female (above right) western black-legged tick. Actual size of the unfed female is about a tenth of an inch. Below, the female (left) and male (right) Pacific Coast tick. Actual size of the unfed female is about an eighth of an inch.

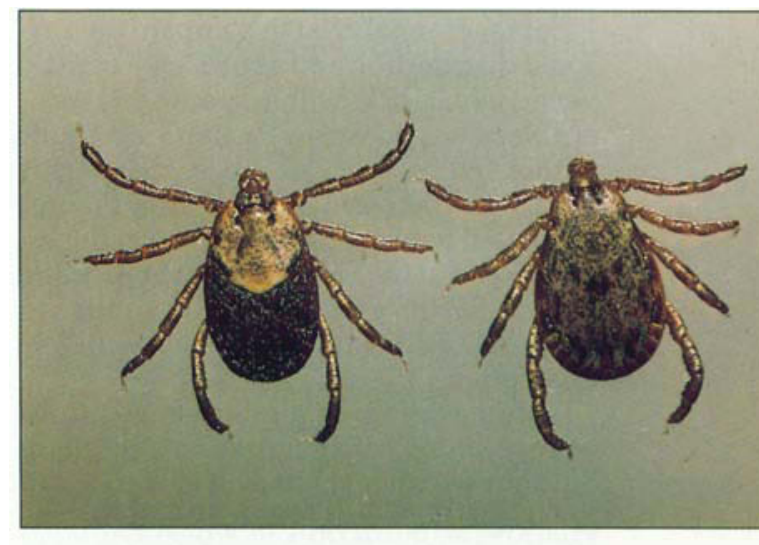

square feet in surface area. Sampling, starting at 8:15 to 9:20 a.m., was conducted at approximately weekly intervals on 69 dates from February 10, 1987 to August 15, 1988. The study site was the south-facing slope of a mountaintop ( 2,900 feet $)$ covered by chaparral and grassland. Chamise (Adenostoma fasciculatum), oaks (Quercus spp.), and California lilac (Ceanothus) were the principal chaparral species; chamise was the dominant plant.

Chaparral abutting grassland was sampled for ticks along four 164-foot transects. The number of drags taken along each transect and the number of adult ticks collected by species and sex were recorded. Each drag-sample was taken by slowly sweeping upward from the base of a plant to a height of 1.6 to 3.3 feet and then downward in an approximate 180-degree arc. Drag-samples were checked individually for ticks, all of which were identified in the field and released on vegetation at the site of capture.

At Sierra Foothill, sampling usually was in the morning, starting at about 8:30, on 38 dates (January 28,1987 , to June 15,1988 ) at one site and on 36 dates (January 29, 1987 to June 9,1988 ) at another. On 9 dates, sampling began in the early afternoon between 2:00 and 3:00 at either site. Blue oak (Quercus douglasii) was the dominant tree species at each site; lesser numbers of Cali- 
fornia black oak (Q. kelloggii) and interior live oak ( $Q$. wislizenii) also were present. One site (K-21) was at an elevation of 1,700 feet and the other (SH1-31) at 650 feet; both sites were on north-facing slopes.

Three 164-foot, parallel transects were established about 33 feet apart in the grass understory at each site. The operator took individual drag-samples as he walked slowly along each transect, laying the drag horizontally on the grass at his right side, then slowly sweeping the drag in front of him in a 180-degree arc to his left. Ticks in each drag-sample were identified to species and sex and released at the site of capture. The number of ticks collected and the number of drags taken per transect were recorded.

Data were analyzed to compare the seasonal distribution and abundance of male versus female ticks within species and western black-legged versus Pacific Coast adults within and between localities (HFS versus SFRFS) and between sites atSFRFS. Figures presented here are based on data gathered at HFS and at the SH1-31 site at SFRFS; site K-21 at SFRFS yielded results similar to those obtained at the SH1-31 site with few exceptions.

Daily maximum-minimum temperatures were recorded with hygrothermographs in outdoor weather shelters at elevations of 2,900 feet (HFS) and 675 feet (SFRFS). The temperatures were averaged over weekly intervals and compared with the seasonal abundance and distribution data gathered for each tick species at each location.

\section{Results}

At Hopland, few western black-legged ticks were collected from chaparral early in 1987 , but a slight fall peak occurred in November (fig. 1). In the first half of 1988, adults became active in January and ceased host-seeking by early June with a pronounced peak of activity in early March (37 ticks per 100 drags). The seasonal distribution and abundance of males and females were similar (data not shown). The small peak of activity in the fall of 1987 occurred when air temperature was approaching its annual low, whereas the much larger peak in early March 1988 occurred after temperatures had risen considerably (maximum and minimum temperatures on the date of peak abundance were $64^{\circ}$ and $44^{\circ} \mathrm{F}$ ).

At both Sierra Foothill sites, the western black-legged tick was active from about mid-fall until mid-spring with a single peak of activity in winter at theSH1-31 site (fig. 2) and identical peaks in fall and winter at the $\mathrm{K}-21$ site (data not shown). The greatest abundance occurred on March 4, 1987 (24 ticks per 100 drags) and on January 21, 1988 (28 ticks per 100 drags) at the $\mathrm{SH} 1-31$ site, and on February 19 and November 20,1987, and February 3, 1988 (each 20 ticks per 100 drags) at K-21. Seasonal occurrence and abundance of females and males were similar at both sites, except that females contributed significantly more than males to the fall 1987 peak, and males contributed more than females to the early February 1988 peak at the K-21 site.

Seasonal western black-legged tick activity appeared to be associated inversely with temperature, beginning in fall as air temperature approached its annual low and peaking in winter as temperatures rose slowly. The maximum and minimum daily temperatures on the single fall and four winter peaks of tick activity at both sites ranged from $54^{\circ}$ to $68^{\circ} \mathrm{F}$ and from $30^{\circ}$ to $54^{\circ} \mathrm{F}$, respectively.

The Pacific Coast tick was usually active at Hopland from winter until late spring/ early summer, with greatest abundance in late winter or early spring (March 7 to 31) (fig. 1). More than twice as many ticks were collected during the seasonal peak in 1988 as in 1987 ( 35 versus 15 ticks per 100 drags). Most tick activity began at about the time daily maximum/minimum temperatures had reached their annual lows and then increased gradually thereafter as temperature increased. The seasonal distributions of female and male ticks overlapped considerably and their abundance was comparable (data not shown).

Similarly, the Pacific Coast tick was active primarily in the winter and spring and, to a lesser degree, in the fall at both Sierra Foothill sites (fig. 2 and data not shown). However, this tick was significantly less abundant at each Sierra Foothill site than at Hopland; the seasonal peaks in abundance
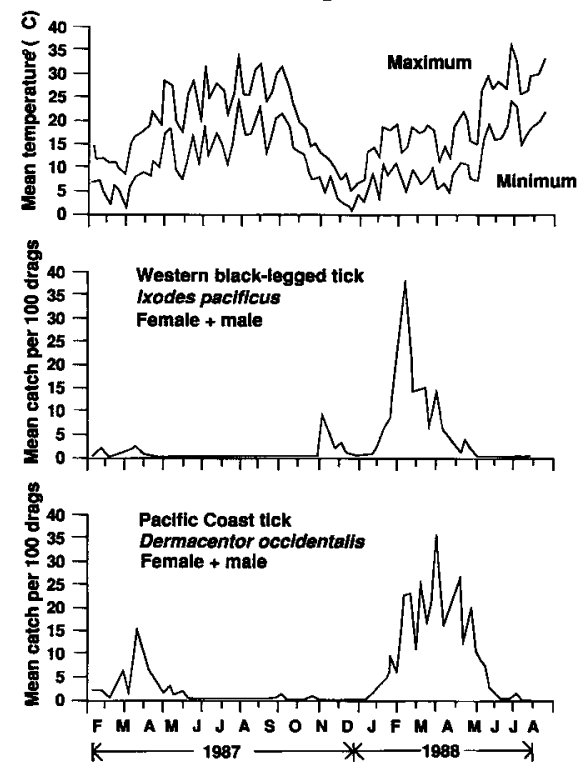

Fig. 1. At Hopland Field Station, adult western black-legged tick activity showed a small peak in the fall of 1987 . WBT was active from January to June 1988 , with a large peak in early March 1988. Pacific Coast tick activity peaked in late winter or early spring. (early February to mid-April) ranged between only 1.4 and 5.8 ticks per 100 drags at Sierra Foothill. There also was considerable variation between sites and years; for example, tick abundance was much greater in the late winter/spring of 1987 than in these same periods in 1988 at the K-21 site, whereas the reverse was true for theSH1-31 site. Seasonal distribution and abundance of females and males were similar, and appeared to be associated with rising midwinter temperatures.

\section{Conclusions}

Adults of both tick species are active mainly during the cooler seasons in coastal (Mendocino) and inland ( $Y u b a$ ) counties of northern California. Other climatological factors besides temperature, either singly or in combination, may influence host-seeking by such ticks: solar radiation, relative humidity (inversely related to temperature in Mediterranean climates), and day-length (photoperiod). Although the seasonal activity periods of these ticks are similar in both counties, considerable variation occurs within sites between years; as shown at $\mathrm{Si}$ erra Foothill, variation in abundance also occurs between sites within years.

Chaparral was swept for ticks at Hopland because it is one of the major vegetational types there, and earlier studies had revealed that it is heavily tick-infested. Chaparral, however, is quite restricted in distribution at Sierra Foothill. Therefore, woodland grass, the predominant vegetational type there, was sampled instead.

The abundance of the western blacklegged tick was comparable at both field
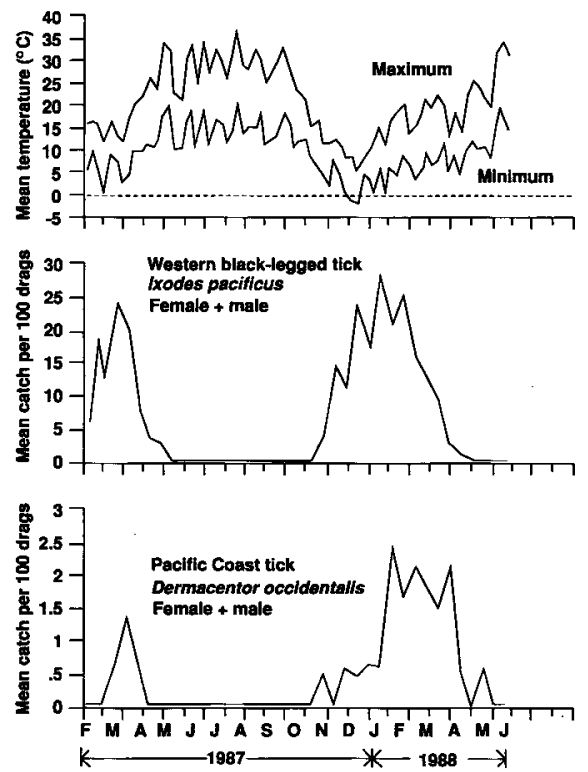

Fig. 2. At the Sierra Foothill Range Field Station site $\mathrm{SH} 1-31$, adult western black-legged ticks were active from mid-fall to mid-spring, peaking in winter. Pacific Coast ticks were active in the winter and spring, and somewhat in the fall. 
stations, but Pacific Coast ticks were much more numerous in chaparral at Hopland than in grassland at Sierra Foothill in both years. The annual activity periods of adults of these two species span several seasons, particularly fall to spring, but the western black-legged tick usually reaches its greatest abundance in mid to late winter, while Pacific Coast tick populations normally peak in late winter to early spring. These tick species seem to have primarily one peak of activity annually, although the western black-legged tick may have a fall peak of variable height preceding a major winter/early spring peak. It is unclear whether the fall peaks observed for the western black-legged tick originated from different or the same cohorts of subadult ticks or merely from sampling differences due to variable climatic conditions.

The seasonal periods of activity of these two tick species on vegetation had not been determined systematically before. An earlier study of western black-legged ticks (primarily adults) on 71 Columbian blacktailed deer at Hopland found that more deer were infested in winter and spring than in summer or fall, but that tick abundance was actually greater in fall and winter. Tick abundance on deer in fall and winter did not differ significantly, but the prevalence of infestation was greater in winter $(100 \%$, $\mathrm{n}=12)$ than in fall $(56 \%, \mathrm{n}=18)$. It is not surprising that these results and my findings agree, since ticks collected with a drag represent the same host-seeking component of the population that infests deer moving through vegetation.

Knowledge of the seasonal activity of all parasitic stages (subadults and adults) of vector ticks is needed to identify periods of greatest risk of exposure to tick-borne agents. Although adults of the western black-legged and Pacific Coast ticks commonly infest people, recent collection records demonstrate that nymphs of these ticks bite humans more often than was realized previously. Moreover, spirochete-infection rates in nymphs of the western black-legged tick are sometimes comparable to those in adult ticks (usually about $1 \%$ to $2 \%$ ).

Besides the Lyme disease spirochete, the western black-legged tick has been found infected naturally with an unclassified rickettsia of the spotted fever group and the bacterial agent that causes tularemia, and it has been implicated as an occasional cause of tick paralysis in dogs. The Pacific Coast tick has been found infected naturally with Colorado tick fever virus, spotted fever group rickettsiae, the agents producing $Q$ fever and tularemia, and, more recently, the Lyme disease spirochete (although less frequently than the western black-legged tick). It also has been implicated as a cause of tick paralysis in cattle, deer, and ponies in California.

Robert S. Lane is Associate Professor, Department of Entomological Sciences, University of California, Berkeley. The author thanks Manfred Hoben, Robert J. Keiffer, Tony Wanzer, and Ken Whittaker, Hopland Field Station, and Tim A. Clark, Sierra Foothill Range Field Station, for collecting ticks; Nancy O'Ferrall, HFS, and Carol L. Hollingsworth, SFRFS, for weather data; and Esther Omi-Olsen and Stephen A. Manweiler, UC Berkeley, for help with data analyses and preparation of figures.

\section{Eucalyptus shows unexpected cold tolerance}

Janine K. Hasey $\square$ J.M.Connor

\begin{abstract}
Although some species of eucalyptus trees in an experimental plantation were damaged in a 1989 cold snap, several species and clones survived temperatures lower than previously thought to be tolerated. The trees are in a low-elevation Sierra foothill test planting used for studies assessing fuelwood growth rates.
\end{abstract}

Eucalyptus are fast-growing hardwood trees used in California for firewood, bio- mass, and pulpwood, but cold sensitivity is a major limitation determining where they can be grown successfully. Many species of this genus commonly planted in California are native to the subtropical regions of Australia and are sensitive to freezing temperatures. Eucalyptus plantings throughout California have suffered damage or have been killed because the species that was planted was not sufficiently cold-tolerant for the site.

One objective of a fuelwood test planting at the Sierra Foothill Range Field Station was to compare cold tolerances of selected eucalyptus species and clones at a low-ele- vation foothill site. In February 1989, an arctic cold front swept through northern California, giving us the unique opportunity to test the limits of reported minimum temperatures that certain eucalyptus species could tolerate.

Fuelwood plantation cultural practices, yield data, and growth characteristics at 3.5 years of age were presented in California $\mathrm{Ag}$ riculture, November-December 1988. Our purpose in this article is to report and illustrate comparative freeze damage, injury ratings, and short-term recovery of the eucalyptus trees in a foothill plantation.

\section{Methods}

In March 1984, six eucalyptus fuelwood species or clones were planted as seedlings in a randomized complete block design with four replications. Each replicated block contains 49 trees planted on 6- by 6foot spacings. A second plot, without replication, was planted for observation purposes in 1986 next to the main plot. It contains four clones also planted on 6-by 6-foot spacings. The elevation at the site is 575 feet with a $7 \%$ slope.

Air temperatures were measured atstandard weather stations on the field station at elevations similar to that of the plantation. Low temperatures measured were $14^{\circ} \mathrm{F}$ on the mornings of February 4 and 5, 1989, and $18^{\circ} \mathrm{F}$ on February 6. Fourteen hours of temperatures below $20^{\circ} \mathrm{F}$ occurred on February 4 , followed by 10 hours below $20^{\circ} \mathrm{F}$ the next day.

The species, clones, seed sources, and minimum temperatures below which severe freeze damage is expected are listed in table 1. Many factors influence the lowest temperature tolerated by a given species, including duration of the cold weather, the temperatures immediately preceding the cold snap, and physiological condition of the tree at the time of the freezing temperatures.

We used a freeze injury rating system with a six-point numerical scale, which was developed by University of California researchers following a severe freeze in northern and central California in 1972 (see table 2 footnotes). Injury was evaluated on two dates. The early rating on March 13,1989, assessed the initial extent of the cold injury. Damage was visually estimated for each species by block (replicate). During the late rating on July 28,1989 , each tree was examined separately for short-term recovery.

\section{Results}

Early evaluations of the 1984 plot showed substantial damage to the $\mathrm{C}-1$ clone and a lesser degree of damage to $E$. globulus (blue gum) (table2). By the time of the later evaluation, the $\mathrm{C}-1$ clone had made considerable recovery. The wide range in ratings within the species grown from seed (non-clones) is 